\title{
Assessment of Knowledge, Attitude, and Disposal Practice of Unused and Expired Pharmaceuticals in Community of Adigrat City, Northern Ethiopia
}

\author{
Halefom Kahsay ${ }^{(D},{ }^{1}$ Mubarek Ahmedin, ${ }^{2}$ Binyam Kebede, ${ }^{3}$ Kiflay Gebrezihar, ${ }^{1}$ \\ Haylay Araya, ${ }^{1}$ and Desta Tesfay $\left(\mathbb{C}^{4}\right.$ \\ ${ }^{1}$ Department of Pharmacy, College of Medicine and Health Science, Adigrat University, Adigrat, Ethiopia \\ ${ }^{2}$ Independent Researcher, Dire Dawa, Ethiopia \\ ${ }^{3}$ Department of Pharmacy, College of Health Science, Debre Markos University, Debre Markos, Ethiopia \\ ${ }^{4}$ Department of Pharmaceutics, School of Pharmacy, College of Health Science, Mekelle University, Mekelle, Ethiopia
}

Correspondence should be addressed to Halefom Kahsay; heleka94@gmail.com

Received 1 October 2019; Revised 28 January 2020; Accepted 12 February 2020; Published 14 April 2020

Academic Editor: Linda M. Gerber

Copyright (c) 2020 Halefom Kahsay et al. This is an open access article distributed under the Creative Commons Attribution License, which permits unrestricted use, distribution, and reproduction in any medium, provided the original work is properly cited.

\begin{abstract}
Background. Medicines have become part of our day-to-day life. Due to different reasons, patients may not use all the medications dispensed to them. The storage of drugs at home promotes self-medication, which results in variety of adverse consequences. Global growth in health-seeking awareness and behavior among people has resulted in increment of medicine consumption over years. However, Ethiopians have little awareness about proper disposal of unused and expired pharmaceuticals. Besides, large quantities remain unused or expired since not all medications given to the consumers are consumed. Hence, this study could serve as an indicator for the country policy makers concerning pharmaceutical waste management. Objective. To assess knowledge, attitude, and disposal practice of unused and expired pharmaceuticals in the community of Adigrat city, Tigray, Ethiopia, 2019. Methodology. A cross-sectional study was conducted among 359 respondents from the residents of Adigrat city. Semistructured questionnaires, which focused on knowledge, attitudes, and disposal practices for unused and expired medications, were used to collect data from respondents. Epi-data 3.0 suite and the statistical package for social sciences (SPSS) version 20 were used in data entry and analysis. Results. All of the 359 returned questionnaires were valid for data entry and analysis. Of the 359 respondents, $57.7 \%$ were men and the majority (93\%) were Orthodox Christians. Almost half of the respondents (50.14\%) have good knowledge concerning the disposal of unused and expired pharmaceuticals. Most (82.2\%) of the respondents have a positive attitude towards the disposal of unused and expired pharmaceuticals. Around fifty-two (52.4) of the respondents had unused medicines stored at home, with analgesics being the most common (41.5\%). Around three-quarters $(75.2 \%)$ and $63 \%$ of the respondents discarded unused and expired medicines in the garbage bins, respectively. Conclusion. Although the majority of the respondents had a positive attitude towards the disposal of unused and expired medications, almost half of the sample population were unaware of proper disposal practices. Furthermore, less were inclined to practice proper disposal of unused and expired medications in the city. Therefore, we recommend further studies that focus on how the disposal attitude of the population can influence their knowledge and practice of the disposal of unused and expired medications.
\end{abstract}

\section{Background}

Medicines have become part of our day-to-day life. Global growth in health-seeking awareness and behavior among people has resulted in increased consumption of medicines over the years. However, patients may not use all of the medications dispensed to them because of many reasons. These include relief of the symptoms, forgetfulness, dosage changes, side effect intolerance, and medications reaching the expiration date. As per the WHO, 50\% of medicines are 
prescribed, dispensed, or sold inappropriately, and half of all patients fail to take them correctly. More than half of all medications are inappropriately prescribed and sold, which poses a risk to environment [1-4]. It can also impose a huge economic burden on the patients as well as the healthcare system. It has been also estimated that billions of dollars' worth of unused medication is wasted every year $[5,6]$. The storage of drugs at home promotes self-medication, which results in a variety of adverse consequences [7-10]. For example, it leads to incidences of drug resistance, loss of potency, toxicity risk, environmental pollution, and incomplete dosage. Although there are options for disposing of unused drugs, many consumers keep drugs in their possession due to unawareness of how to dispose of them properly. In addition, a recent review suggests that consumers use different methods for disposing unused medicines, with the most commonly being throwing medicines in garbage, toilet, or sink $[11,12]$.

Although a few studies have been done to assess the knowledge, attitude, and disposal practice of unused and expired pharmaceuticals among households in Ethiopia, there is still a dearth of information regarding the disposal practices for unused medications in areas like Adigrat city. Therefore, this study was conducted to assess the knowledge, attitudes, and disposal practices for unused and expired medications among the residents of Adigrat city. Generally, this survey could serve as an indicator for environmental policy makers. On the other hand, it could be used as indicator for responsible offices of Adigrat city to take appropriate measures regarding the disposal of unused and expired pharmaceuticals.

\section{Methods}

A community-based cross-sectional study with a multistagesampling technique was conducted in Adigrat city, Tigray regional state, Northern Ethiopia. Individuals over 18 years (207 males and 152 females) with sound mental health were selected for the study. The sample size was calculated using a single population proportion formula, by using a margin of error of 0.05 and a proportion of event occurrence at $66.6 \%$ similar to another study conducted in Eastern Ethiopia at a $95 \%$ of level of significance by adding a 5\% nonresponse rate. Based on the above assumption, the minimum sample size required for the study was 359. Proportional random sampling technique was used to select households from each kebele (i.e., the smallest administrative unit of Ethiopia) of the Adigrat city (Figure 1). Data was collected through interviews using a previously adopted standard questionnaire that was also translated into local languages. The translated data was then checked for errors in communication resulting from mistranslations. Data analysis was performed using SPSS Statistics software. Sociodemographic data and the levels of KAP of the study participants related to unused and expired pharmaceuticals were measured, with frequencies for descriptive variables and binary logistic regression undertaken, to explore the factors associated with the knowledge, attitudes, and practices of the respondents $(P \leq 0.05)$ at a $95 \%$ confidence interval $(\mathrm{CI})$.
Bivariate association between dependent and independent variables was determined, and covariates with $P \leq 0.2$ with the outcome variable were dropped from further consideration in modeling by using multivariate analysis as an adjusted OR (AOR). Individuals who had a knowledge score of at least three out of the five questions were considered as having good knowledge concerning unused and expired medication disposal, and those who scored less than two were considered as having poor knowledge [13]. Similarly, those individuals who answered with "strongly agree" and "agree" to the questions were considered to have a positive attitude concerning unused and expired medication disposal, while those who answered with "strongly disagree" and "disagree" to the questions were considered to have a negative attitude. The study was reviewed by the Ethics Committee of the School of Pharmacy at Adigrat University and was granted ethical clearance. Permission was also obtained from the Adigrat city Health Office to conduct the study in the city. Prior to data collection, informed consent was obtained from the participants.

\section{Results}

3.1. Sociodemographic Characteristics of the Respondents. All the approached 359 individuals agreed to participate in the study. Of the 359 respondents, 207 (57.7\%) were males. The majority $(137 ; 38.2 \%)$ of the respondents were 32 years old and above. Concerning their educational level, one hundred and twelve (31.2\%) respondents completed secondary education, $178(49.6 \%)$ had a college/university degree and above, and $31(8.6 \%)$ were illiterate. Of the total respondents, 334 (93\%) were Orthodox Christians (Table 1).

\subsection{Respondents Knowledge concerning Unused and Expired} Medication Disposal. As presented in Table 2 the respondents gave possible answers about awareness of unused and expired medication disposal. On assessing the knowledge score, this study found that about $50.14 \%$ of respondents have good knowledge. Furthermore, most of the respondents $(87.2 \%)$ knew about drug resistance. On the other hand, a large portion of the respondents $(87.2 \%)$ did not know about drug-take-back systems. The majority of the respondents (95\%) felt that improper disposal of unused and expired medicines has detrimental effects on the environment and health. In multivariate logistic regression tests, those who did not have any level of educational attainment were nearly 0.66 times $(\mathrm{AOR}=0.338,95 \%$ $\mathrm{CI}=0.102-1.121)$ more likely to have poor knowledge concerning unused and expired medication disposal in their households compared to those who have college/ university and above educational status. However, the presence of higher education levels attained in households did not show a statistically significant difference in unused and expired medication disposal (Table 3). A majority (35.9\%) of the respondents responded as pharmacists were the responsible bodies in creation of awareness about proper disposal of medicines to them (Figure 2). 


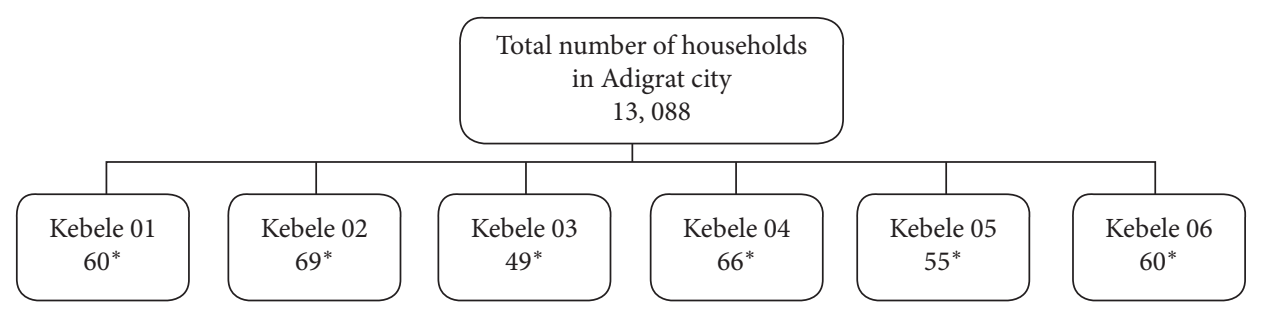

Figure 1: The schematic presentation of total number of households and sample taken in each kebele of Adigrat city, 2019.

TABLE 1: Sociodemographic characteristics of respondents in Adigrat city, Northern Ethiopia, $2019(N=359)$.

\begin{tabular}{|c|c|c|}
\hline Variables and categories & $(N=359)$ & $\%$ \\
\hline \multicolumn{3}{|l|}{ Gender } \\
\hline Male & 207 & 57.7 \\
\hline Female & 152 & 42.3 \\
\hline \multicolumn{3}{|l|}{ Age } \\
\hline $18-24$ & 134 & 37.3 \\
\hline $25-31$ & 88 & 24.5 \\
\hline$>31$ & 137 & 38.2 \\
\hline \multicolumn{3}{|l|}{ Marital status } \\
\hline Single & 134 & 37.3 \\
\hline Married & 207 & 57.7 \\
\hline Divorced & 6 & 1.7 \\
\hline Widowed & 12 & 3.3 \\
\hline \multicolumn{3}{|l|}{ Profession/occupation } \\
\hline Governmental employee & 108 & 30.1 \\
\hline Self-employed & 133 & 37 \\
\hline Housewife & 29 & 8.1 \\
\hline Farmer & 8 & 2.2 \\
\hline Student & 79 & 22 \\
\hline Other*** & 2 & 0.6 \\
\hline \multicolumn{3}{|l|}{ Monthly income (ETB) * } \\
\hline$<1380$ (poor) & 156 & 43.5 \\
\hline 1381-6900 (low) & 155 & 43.2 \\
\hline 6901-13800 (middle) & 45 & 12.5 \\
\hline$>13800$ (high) & 3 & 0.8 \\
\hline \multicolumn{3}{|l|}{ Education level } \\
\hline Illiterate & 31 & 8.6 \\
\hline Primary [1-8] & 38 & 10.6 \\
\hline Secondary $[9-12]$ & 112 & 31.2 \\
\hline College/university student and & 178 & 49.6 \\
\hline \multicolumn{3}{|l|}{ Above } \\
\hline \multicolumn{3}{|l|}{ Religion } \\
\hline Orthodox & 334 & 93 \\
\hline Muslim & 12 & 3.3 \\
\hline Protestant & 2 & 0.6 \\
\hline Catholic & 11 & 3.1 \\
\hline
\end{tabular}

${ }^{*}$ Classified according to World Bank income level scale for developing countries; ETB: Ethiopian birr; ${ }^{* * *}$ unemployed.

3.3. Respondents Attitude concerning Unused and Expired Medication Disposal. Possession of unused medication was mostly due to resolving disease or conditions/improving symptoms (51\%), forgetting to take it $(25.6 \%)$, changing of medication by the doctor (17\%), and experiencing side-effects (3.6\%) (Figure 3). As shown in Figure 4, most of the respondents $(72.4 \%)$ suggested that proper guidance should be given to the consumer. In response to a question about the best means to create awareness of proper drug disposal practices, $48.7 \%$ considered advertising through electronic media and $27.3 \%$ considered the physician responsible, while the rest were in favor of all sources, including the pharmacy staff and newspapers (Figure 5).

On assessing attitude scores, over eighty-percent $(82.2 \%)$ of the respondents have positive attitude towards the disposal of unused and expired pharmaceuticals. Nearly half $(48.7 \%)$ of the respondents "strongly agreed" to the extent that they believe that unused and expired medicines present potential risks or negative consequences at home. Additionally, $44.8 \%$ of the respondents stated that they "strongly agreed" that the risks of unused and expired medicines to children are greater, while $24.5 \%$ of the 
TABLE 2: Respondents knowledge concerning unused and expired medication disposal in Adigrat city, Northern Ethiopia, $2019(N=359)$.

\begin{tabular}{|c|c|c|c|}
\hline \multirow{2}{*}{ No. } & \multirow{2}{*}{ Questions } & \multicolumn{2}{|c|}{ Answer } \\
\hline & & Yes & No \\
\hline 1 & Do you know about medication waste? & $\begin{array}{c}178 \\
(49.6 \%)\end{array}$ & $\begin{array}{c}181 \\
(50.4 \%)\end{array}$ \\
\hline 2 & Have you ever read medicines disposal instructions? & $\begin{array}{c}143 \\
(39.8 \%)\end{array}$ & $\begin{array}{c}216 \\
(60.2 \%)\end{array}$ \\
\hline 3 & Do you know about "drug-take-back system"? & $46(12.8 \%)$ & $\begin{array}{c}313 \\
(87.2 \%)\end{array}$ \\
\hline 4 & Do you know that misused/repeated change or not complete antibiotics may cause drug resistance? & $313(87.2 \%)$ & $46(12.8 \%)$ \\
\hline \multirow[t]{2}{*}{5} & $\begin{array}{c}\text { Do you know that improper disposal of unused and expired medicines can affect the environment and } \\
\text { health? }\end{array}$ & $\begin{array}{c}344 \\
(95.8 \%)\end{array}$ & $15(4.2 \%)$ \\
\hline & $\begin{aligned} & * \text { Knowledge score } \\
& \\
& \bullet \text { Good knowledge: } 180(50.14 \%) \\
& \bullet \text { Poor knowledge: } 179(49.86 \%)\end{aligned}$ & & \\
\hline
\end{tabular}

* Score 0-2: poor knowledge, score 3-5: good knowledge.

TABLE 3: Multivariate logistic regression analysis results of sociodemographic characteristics of the respondents associated with their knowledge about the disposal of unused and expired medication in Adigrat city, Northern Ethiopia, 2019.

\begin{tabular}{|c|c|c|c|c|c|}
\hline \multirow{2}{*}{ Characteristics } & & \multicolumn{2}{|l|}{ COR } & \multicolumn{2}{|l|}{$\mathrm{AOR}$} \\
\hline & & COR (CI95\%) & $P$-value & AOR (CI 95\%) & $P$-value \\
\hline \multirow{3}{*}{ Sex } & Male & $1.010(0.65-1.535)$ & 0.964 & $0.825(0.499-1.366)$ & 0.456 \\
\hline & Female & 1.00 & & 1.00 & \\
\hline & $18-24$ & $2.016(1.243-3.270)$ & 0.004 & $1.824(0.875-3.798)$ & 0.109 \\
\hline \multirow[t]{2}{*}{ Age (in years) } & $25-31$ & $1.404(0.819-2.405)$ & 0.217 & $1.506(0.800-2.833)$ & 0.204 \\
\hline & $>31$ & 1.00 & & 1.00 & \\
\hline \multirow[t]{6}{*}{ Marital status } & Single & $0.741(0.212-2.583)$ & 0.638 & $0.767(0.189-3.111)$ & 0.711 \\
\hline & Married & $0.377(0.110-1.292)$ & 0.121 & $0.528(0.134-2.083)$ & 0.361 \\
\hline & Divorced & $0.500(0.068-3.696)$ & 0.497 & $0.826(0.087-7.856)$ & 0.868 \\
\hline & Widowed & 1.00 & & 1.00 & \\
\hline & Governmental Employee & $0.964(0.059-15.805)$ & 0.979 & $0.980(0.051-18.962)$ & 0.990 \\
\hline & Self-employed & $0.928(0.057-15.141)$ & 0.958 & $1.226(0.065-23.011)$ & 0.892 \\
\hline \multirow{5}{*}{$\begin{array}{l}\text { Profession/ } \\
\text { occupation }\end{array}$} & Housewife & $0.611(0.035-10.794)$ & 0.737 & $1.448(0.067-31.230)$ & 0.813 \\
\hline & Farmer & $1.667(0.074-37.728)$ & 0.748 & $10.024(0.299-336.469)$ & 0.199 \\
\hline & Student & $1.394(0.084-23.099)$ & 0.817 & $2.388(0.118-48.405)$ & 0.571 \\
\hline & Other & 1.00 & & 1.00 & \\
\hline & $\leq 1380$ & $0.429(0.038-4.825)$ & 0.493 & $0.174(0.013-2.362)$ & 0.189 \\
\hline Monthly income & $1381-6900$ & $0.457(0.041-5.142)$ & 0.526 & $0.387(0.031-4.850)$ & 0.462 \\
\hline \multirow[t]{2}{*}{ (in ETB birr) } & $6901-13800$ & $1.231(0.103-14.778)$ & 0.870 & $1.262(0.099-16.233)$ & 0.856 \\
\hline & $>13800$ & 1.00 & & 1.00 & \\
\hline \multirow[t]{2}{*}{ Education } & Illiterate & $0.253(0.107-0.597)$ & 0.002 & $0.338(0.102-1.121)$ & 0.076 \\
\hline & Primary school [1-8] & $0.379(0.182-0.788)$ & 0.009 & $0.581(0.235-1.433)$ & 0.238 \\
\hline \multirow[t]{3}{*}{ Level } & Secondary school (9-12) & $0.728(0.453-1.171)$ & 0.191 & $0.892(0.497-1.600)$ & 0.700 \\
\hline & College/university and above & 1.00 & & 1.00 & \\
\hline & Orthodox & $11.139(1.410-87.996)$ & 0.022 & $10.797(1.205-96.717)$ & 0.033 \\
\hline \multirow{3}{*}{ Religion } & Muslim & $3.333(0.292-38.082)$ & 0.333 & $3.599(0.266-48.641)$ & 0.335 \\
\hline & Protestant & 0.000 & 0.999 & 0.000 & 1.000 \\
\hline & Catholic & 1.00 & & 1.00 & \\
\hline
\end{tabular}

The relationship is significant at $p<0.05$.

respondents "strongly agreed" that a lack of adequate information on safe disposal practices is a precursor to the risks and negative consequences of unused and expired medicines. In contrast, $1.9 \%$ of the respondents "strongly disagreed" that there is adequate advice by doctors and healthcare professionals on safe disposal practices with a further $2.5 \%$ "strongly disagreeing" that a lack of adequate information on safe disposal practices is a precursor to the risks and negative consequences of unused and expired medicines. Concerning take-back programs, the respondents gave varying opinions. Over ten percent $(11.4 \%)$ strongly agreed that the programs should be mandatory. However, the respondents inclined to accept mandatory take-back programs $(25.9 \%)$ were fewer than those who were not in favor of them (62.1\%), whereas only $12 \%$ remained neutral (Table 4 ). 


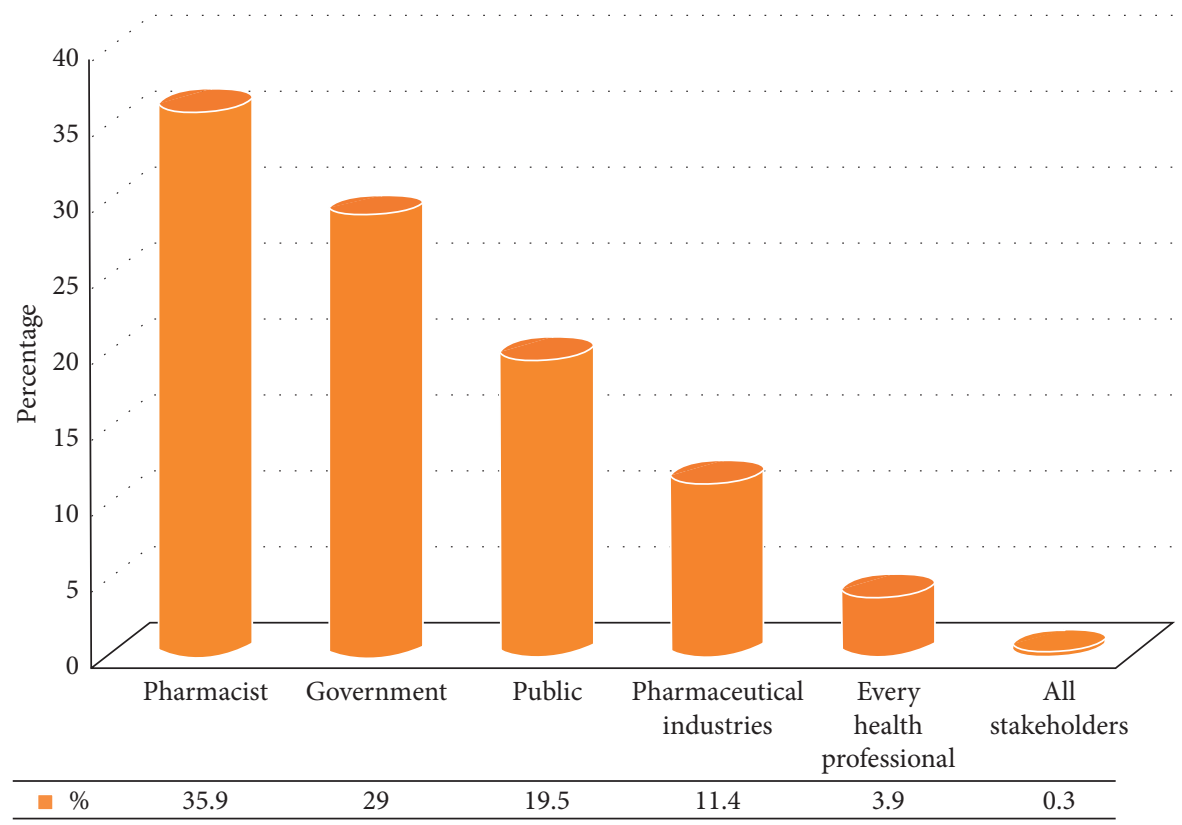

FIGURE 2: Bodies responsible for creation of awareness about proper medicine disposal in Adigrat city, Northern Ethiopia, 2019 ( $N=359)$.

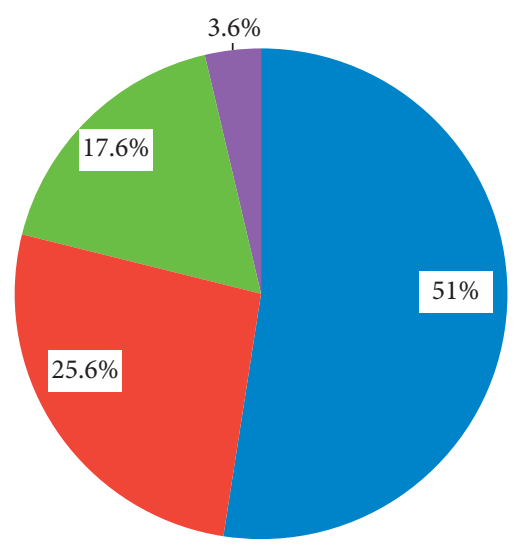

Reasons for possessing unused medications

- Disease or condition resolved/symptoms improved

- Forgetting to take it

- Change of medication by the doctor

- Experiencing side-effect

FIGURE 3: Respondents' reasons for keeping purchased medicine unused at home in Adigrat city, Northern Ethiopia, 2019 ( $N=359)$.

3.4. Respondents Practice on Unused and Expired Medication Disposal. Approximately $52.4 \%$ of the respondents had unused medicine stored at home, but $47.6 \%$ of the respondents did not have unused medicines stored at home (Figure 6).

The common types of medicines kept in households were analgesics (41.5\%) and antibiotics (36.7\%). In addition, antipain and antibiotic (4.8\%), antidiabetic (5.3\%), and antihypertensive ( $8 \%$ ) medicines were other types of unused medications found in homes (Table 5).

The most preferred disposal practice for unused medicines was throwing them in garbage bins (63\%) followed by giving them to friends or relatives $13.9 \%$. Some of respondents $(4.2 \%)$ keep unused medicines at home until they become expired, while $1.9 \%$ and $6.7 \%$ of the respondents indicated that they burn and donate medicines to hospitals, respectively. About (7\%) respondents considered that returning unused medicines to the pharmacies would be the best option (Table 6).

The most preferred disposal practice for expired medicines was throwing them in garbage bins (75.2\%) followed by flushing them in the toilets (15\%). Some respondents $(3.9 \%)$ said that they did not know what to do with the 


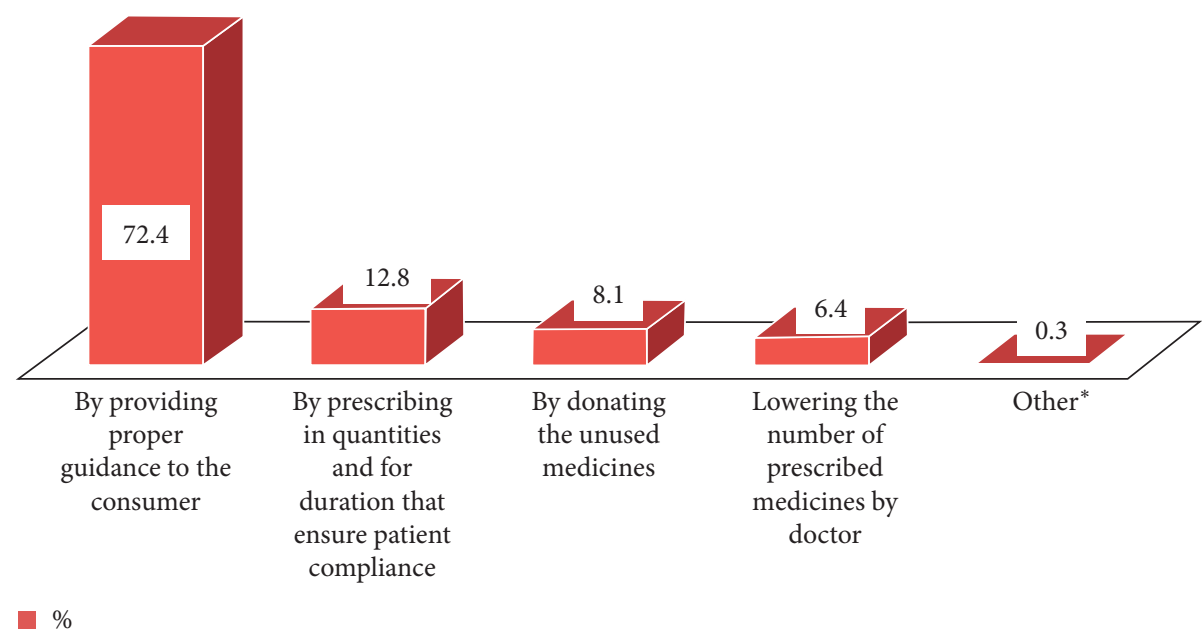

FIgURe 4: Actions that should be taken to minimize or control the hazardous effect of unused and expired medicines in Adigrat city, Northern Ethiopia, $2019(N=359) .{ }^{*}$ Keeping in safe place, disposing in toilet, and burning.

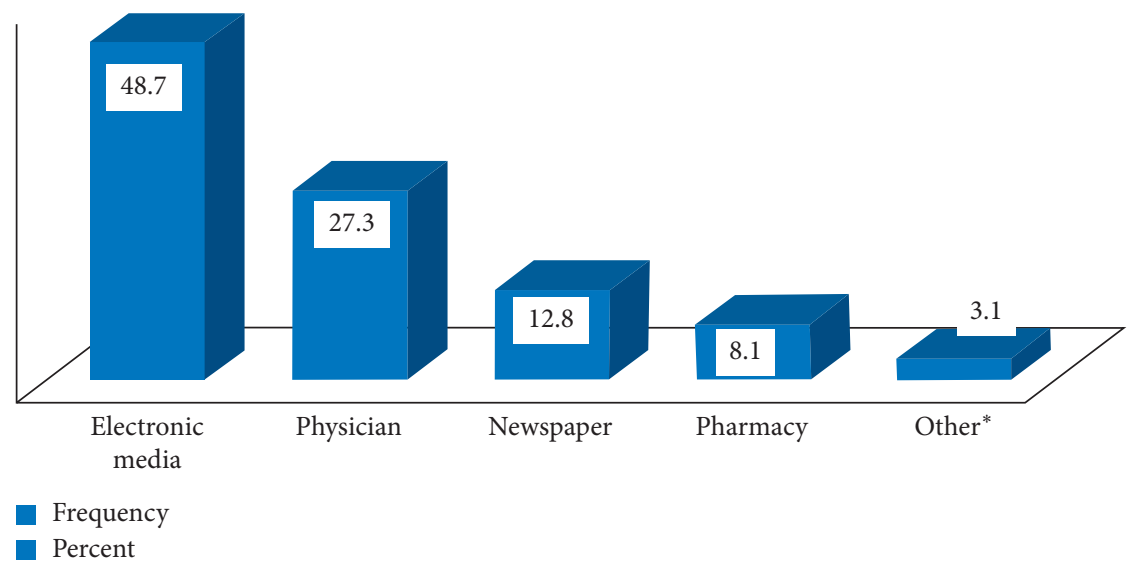

Figure 5: Householders' attitudes towards best source of awareness for society in Adigrat city, Northern Ethiopia, $2019(N=359) .{ }^{*}$ Health bureau, environmental agency, and drug regulatory agency.

Table 4: Attitudes towards unused and expired medicines among households in Adigrat city, Northern Ethiopia, 2019 ( $N=359)$.

\begin{tabular}{|c|c|c|c|c|c|c|}
\hline \multirow{2}{*}{ No. } & \multirow{2}{*}{ Attitudes of respondents } & \multicolumn{5}{|c|}{ Number of respondents (\%) } \\
\hline & & Strongly disagree & Disagree & Neutral & Agree & Strongly agree \\
\hline 1 & $\begin{array}{l}\text { Unused and expired medicines present potential risks at } \\
\text { home }\end{array}$ & $4(1.1)$ & $6(1.7)$ & $4(1.1)$ & $170(47.4)$ & $175(48.7)$ \\
\hline 2 & Children are more vulnerable & $3(0.8)$ & $4(1.1)$ & $1(0.3)$ & $190(52.9)$ & $161(44.8)$ \\
\hline 3 & $\begin{array}{l}\text { Lack of adequate information on } \\
\text { safe disposal }\end{array}$ & $9(2.5)$ & $13(3.6)$ & $12(3.3)$ & $237(66)$ & $88(24.5)$ \\
\hline 4 & $\begin{array}{l}\text { Advise by doctors and healthcare professionals should be gi } \\
\text { ven }\end{array}$ & $7(1.9)$ & $24(6.7)$ & $11(3.1)$ & $207(57.7)$ & $110(30.6)$ \\
\hline \multirow[t]{2}{*}{5} & $\begin{array}{l}\text { Take-back programs of unused and expired medicines should } \\
\text { be mandatory }\end{array}$ & $78(21.7)$ & $145(40.4)$ & $43(12)$ & $52(14.5)$ & $41(11.4)$ \\
\hline & $\begin{array}{ll}\text { Specific response } & \\
& * \text { Attitude } \\
& \bullet \text { Positive attit } \\
& \bullet \text { Negative at }\end{array}$ & $\begin{array}{l}\quad 7 \\
\text { e status score } \\
\text { tude: } 295(82.2 \%) \\
\text { titude: } 21(5.8 \%)\end{array}$ & 14 & 43 & 214 & 81 \\
\hline
\end{tabular}

*Score for positive attitude: "strongly agree" and "agree"; score for negative attitude: "strongly disagree" and "disagree." 

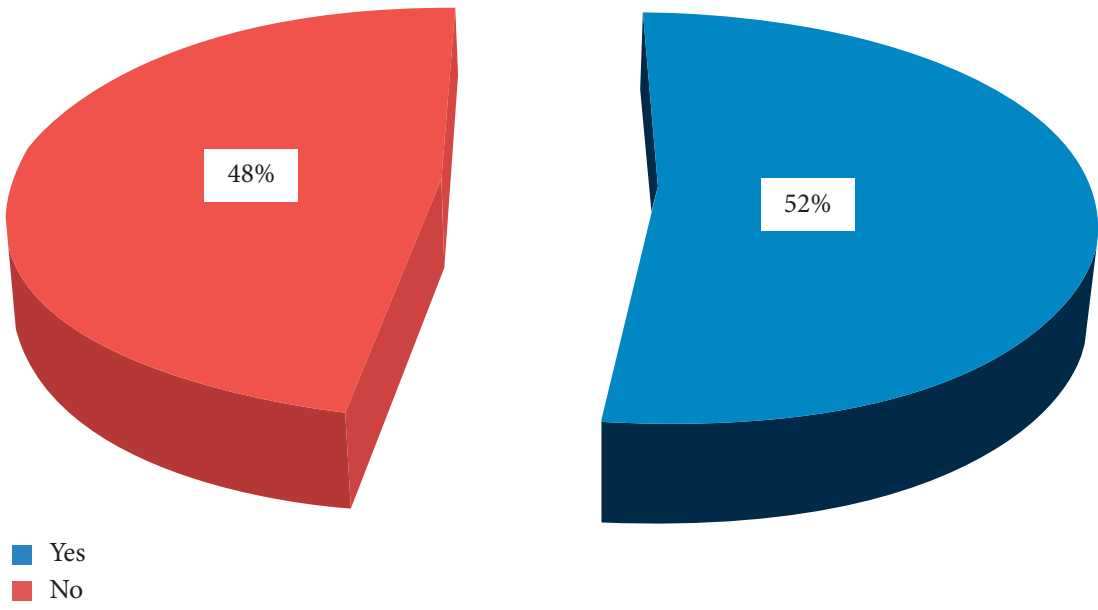

Figure 6: Purchased medicines remaining unused at home among households in Adigrat city, Northern Ethiopia, 2019 (N=359).

TABLE 5: Types of medications remaining unused at home among households in Adigrat city, Northern Ethiopia, $2019(N=359)$.

\begin{tabular}{lcc}
\hline Types of medications remaining unused at home & $N$ & \% \\
\hline Analgesic & 78 & 41.5 \\
Antibiotic & 69 & 36.7 \\
Antihypertensive & 15 & 8 \\
Antidiabetic & 10 & 5.3 \\
Both analgesic and antibiotic & 9 & 4.8 \\
Other medications* & 7 & 3.7 \\
\hline
\end{tabular}

*Antihelminthics.

TABLE 6: Disposal practice of unused medicines among households in Adigrat city, Northern Ethiopia, $2019(N=359)$.

\begin{tabular}{lcc}
\hline Disposal practice of unused medicines & $N$ & $\%$ \\
\hline Throwing them away in household garbage & 226 & 63 \\
Donating them to hospital & 24 & 6.7 \\
Giving them to friends or relatives & 50 & 13.9 \\
Returning them back to pharmacy & 25 & 7 \\
Keeping them at home until expired & 15 & 4.2 \\
Flushing them in toilet & 12 & 3.3 \\
Burning them & 7 & 1.9 \\
Total & 359 & 100 \\
\hline
\end{tabular}

expired medicines, while $2.5 \%$ and $0.8 \%$ of the respondents reported that they would return them to pharmacy and give them to friends or relatives, respectively (Table 7).

Above two-third of respondents discarded the expired medications as they are, 5.8\% did not know about the practice of expired medication disposal, $8.1 \%$ crushed them before discarding, and only $4.2 \%$ said that expired medications are thrown after dilution (Table 8).

\section{Discussion}

The proper collection and disposal of unused and expired medications through a well-run disposal system and collection programs have implications for ensuring public safety for humans and safeguarding the natural environment. Although medication disposal is a hot topic gaining attention across the world because it has been realized that
TABLE 7: Disposal practice of expired medicines among households in Adigrat city, Northern Ethiopia, $2019(N=359)$.

\begin{tabular}{lcc}
\hline Disposal practice of expired medicines & $N$ & $\%$ \\
\hline Throwing them away in household garbage & 270 & 75.2 \\
Flushing them in toilet & 54 & 15 \\
Giving them to friends or relatives & 3 & .8 \\
Returning them back to pharmacy & 9 & 2.5 \\
Do not know & 14 & 3.9 \\
Other & 9 & 2.5 \\
Total & 359 & 100 \\
\hline
\end{tabular}

TABLE 8: Ways of discarding expired medicines among households in Adigrat city, Northern Ethiopia, $2019(N=359)$.

\begin{tabular}{lcc}
\hline Ways of discarding expired medicines & $N$ & $\%$ \\
\hline Crushing them before discarding & 29 & 8.1 \\
Diluting them with water & 15 & 4.2 \\
As they are & 294 & 81.9 \\
Do not know & 21 & 5.8 \\
Total & 359 & 100 \\
\hline
\end{tabular}

improper disposal can contaminate the environment $[14,15]$, this study shows that over eighty percent $(87.2 \%)$ of the respondents did not know about drug-take-back systems, which is consistent with studies conducted in Bangladesh $(96.8 \%)$ and Malaysia $(93.6 \%)[6,16]$ and higher than a study conducted in Harar city (66.9\%) [17]. Even though $12.8 \%$ of the respondents in the current study knew about drug-take-back systems, only $7 \%$ and $2.5 \%$ of the respondents returned unused and expired medicines back to the pharmacy, respectively. This might be due to a lack of established drug-take-back system in Adigrat city. On the other hand, most of the respondents (87.2\%) knew about drug resistance; although this was lower than a study conducted in Bangladesh (96.55\%) [6], it is higher than that in Harar city $(78.1 \%)$ [17]. The difference from the study conducted in Harar city might be because pharmacists and other healthcare professionals in Adigrat city create adequate awareness about drug resistance and its associated problems. The emergence of resistance during therapy has been shown to significantly affect outcomes negatively [18]. 
The majority of the respondents (95.8\%) were aware of the hazardous environmental and health impact of improper disposal of unused and expired medicines. This is comparable to findings in Afghanistan, where most participants (98\%) felt that improper disposal of unused and expired medicines can affect the environment and health [19]. However, this finding is higher than the results from Karachi city (80\%) and Harar city $(86 \%)[17,20]$. This study found that about $50.14 \%$ of the respondents have good knowledge. This might be because healthcare professionals in Adigrat city show their interest in creating awareness about the negative impacts of improper disposal of unused and expired medicines. It may also be because governmental bodies provide adequate training for those healthcare professionals about this issue [1].

The current study shows that $52.4 \%$ of the respondents had leftover, unused, or unwanted medications, which is lower than the results of studies conducted in India and Harar city, where 68 and $66 \%$ of the respondents, respectively, stored unused medicines at home $[17,21]$. In this study, the common types of medications kept in households were analgesics (41.5\%) and antibiotics (36.7\%), which is inconsistent with studies conducted in Harar, USA, and Nigeria for analgesics $(62.7 \%, 15 \%, 18.6 \%)$ and antibiotics $(24 \%, 6.7 \%, 16.8 \%)$, respectively $[5,17,22]$. An excess of those medications at home may be due to the idea of ready prevention of infectious diseases without referral to a doctor, and pain is associated with many diseases that patients may consider treatable with analgesics in Adigrat city. Therefore, these results imply a high prevalence of self-medication. Indeed, an increased amount of antibiotics at home may lead to antibiotic resistance. The storage of unwanted or unused medication in the household provides an increased risk of accidental childhood poisonings. Reasons for possessing unused medication were mostly a disease or condition that resolved, with symptoms improved (51\%), or forgetting to take it $(25.6 \%)$. This excess of medications in homes leads to the issue of inappropriate disposal and has potential implications for accidental childhood ingestion [23, 24].

In order to minimize the entry of pharmaceuticals into environment, $72.4 \%$ of the respondents in this study suggested that proper guidance should be given to the consumer and $12.8 \%$ of the respondents suggested that medication should be prescribed in smaller quantities and only for time periods that ensure patient compliance. This result is inconsistent with a study conducted in Karachi city where 33\% suggested that proper guidance should be given to the consumer, with $37 \%$ of the respondents advocating for short-term trial prescriptions [6]. In contrast, $68.6 \%$ of the respondents advocated for more guidance that is proper and $17.7 \%$ for trial prescriptions in the Harar study [17]. Differences in suggestion might be affected by the inadequate level of advice given by health professionals in Adigrat. Because this study found that about $82.2 \%$ of the respondents have positive attitude towards disposal of unused and expired pharmaceuticals, it is likely that better advice and guidance from healthcare professionals may contribute to a better practice of proper disposal.

The most preferred disposal practice for unused medicines was throwing them in garbage bins (63\%) followed by giving them to friends or relatives $(13.9 \%)$, while some respondents suggested donation to pharmacy (7\%). From a study carried out in New Zealand, it became evident that more than $35 \%$ of the respondents considered it acceptable to flush down unused medicines in the toilet and more than $21 \%$ believed that it is acceptable to rinse them down the kitchen sink [19]. Another study conducted in Harar city showed that most of the respondents preferred throwing unused medications in garbage bins (53.2\%) followed by flushing them in the toilets (23.9\%), while some respondents (16\%) kept unused medicine at home until they expired [17]. This difference might be due to garbage bins being more easily available around compounds and lack of awareness about proper disposal practices of medications in Adigrat city

Approximately two-thirds (75.2\%) of respondents in this study assert that they throw away the expired medicines in the household trash while $15 \%$ of the respondents flush down expired medicines in the toilets. From a study carried out in Afghanistan, it is evident that around 78\% of the respondents throw away expired medicines in household garbage and 12\% of respondents flush expired medications in toilet or sink [19]. A study conducted in Harar shows that one-half (50\%) of respondents throw away the expired medicines in the household trash while $37.2 \%$ of the respondents flush down expired medicines in the toilets. This difference might be because respondents believe that expired medications should be flushed down into the toilet in order to prevent accidental childhood and environmental poisoning. According to the current study, most of the methods for disposal of unused and expired medicines followed by the respondents are not recommended methods, though they are commonly used in many places. Nevertheless, the recommended method for disposal of most pharmaceuticals is high temperature incineration (as it oxidizes all organic material into carbon dioxide and renders them inert to any toxicological effect in the environment), which requires some initial organized method of collecting and sorting. Nowadays, in many developed countries, drug-take-back systems are established for collection of unused and expired medicines. One type of drug-take-back program that has been suggested by "Nebraska Medication Education for Disposal Strategies (MEDS)" is to put tamper-resistant boxes in pharmacies that will allow consumers to bring medicines back to knowledgeable pharmacists. For example, in Sweden and Korea, more people return unused medicines to a pharmacy for correct disposal, as they have realized the environmental concerns posed by expired medicines [25-27].

In order educate the community about proper disposal of unused and expired medication, it is important to increase awareness among the public through the government, pharmacists, and pharmaceutical industries. A significant role can be played by community pharmacists being on the forefront in guiding the community and providing it with proper education and awareness [28]. Therefore, the government of Ethiopia should be committed to encourage feasible expired pharmaceutical collection programs. However, stronger campaigns and significant involvement of the patient, healthcare professionals, and the government officials are required, in order to avoid any possible barriers 
such as lack of information about techniques of proper disposal of expired medication [29]. Additionally, the White House Office of National Drug Control Policy recommends household trash disposal if take-back programs are unavailable. Prescription medicines along with the patient information should be removed from their original containers, mixed with some undesirable substance, such as kitty litter, coffee grounds, or sawdust inside a sealable plastic bag container, and disposed of in the trash. In addition, the American Pharmacists Association also recommends that unwanted medications should be crushed or dissolved in water prior to mixing with the undesirable substance [30,31].

Above two-thirds (81.9\%) of respondents in the current study discarded expired medications. However, the FDA recommends that expired medications should be initially mixed (without crushing tablets or capsules) with an unpalatable substance such as dirt, cat litter, or used coffee grounds. Then, the mixture should be placed in a container such as a sealed plastic bag, and the container should be thrown in household trash. However, before throwing the container, all personal information on the prescription label of empty pill bottles or medicine packaging should be deleted [32]. Multivariate logistic regression tests showed that sociodemographic characteristics of the respondents affected knowledge concerning unused and expired medication disposal. Those with no formal educational achievements were nearly 0.66 times $(\mathrm{AOR}=0.338,95 \%$ $\mathrm{CI}=0.102-1.121)$ more likely to have poor knowledge concerning unused and expired medication disposal in their households compared to those who have college/ university and above education status. However, the presence of highest education levels attained in households did not show a statistically significant difference in knowledge from those with lower standards. On the other hand, those who are Orthodox Christians are nearly 11 times more likely to have knowledge about unused and expired medication disposal in their households compared with those who followed Catholicism (AOR $=10.797,95 \%$ $\mathrm{CI}=1.205-96.717)$. However, this result is tentative since disparities in the sampling between participants from different religions could exist. Therefore, further investigations are needed to justify this finding. Indeed, the limitations of the study, most importantly the cross-sectional nature of the study design, prevent us from drawing causal inferences about the relationship between the chosen covariates and outcome variables over a period. Based on the findings, it could be a challenge to infer the present results about the status of knowledge, attitudes, and disposal practices of unused and expired pharmaceuticals in other areas of Ethiopia. Additionally, this study has a dispute in data collection because of the dislocation existence of new households and old data taken regarding the houses included in the study area.

\section{Conclusion}

The study indicates that improper discarding of medications seems to be practiced in Adigrat city. A large portion of the respondents did not know about drug-takeback systems. On the other hand, most of the respondents had a positive attitude towards the risks of unused and expired medications. Almost half of the respondents suggested that awareness regarding disposal of unused and expired pharmaceuticals should be improved. There is a pressing need for increasing awareness about proper disposal of unused and expired medicines among the public. Community pharmacists can play a significant role in encouraging proper disposal practices in Adigrat city.

\author{
Abbreviations \\ APHA: American Pharmacists Association \\ CSA: $\quad$ Central statistical agency \\ FDA: $\quad$ Food and Drug Administration \\ HH: $\quad$ Households \\ NSAID: Nonsteroidal anti-inflammatory drug \\ OTC: $\quad$ Over the counter \\ ONDCP: Office of National Drug Control Policy \\ UEM: $\quad$ Unused and expired medicines \\ FMHACA: Food, Medicine and Healthcare Administration \\ and Control Authority.
}

\section{Data Availability}

The dataset used to support the findings of this study are available from the corresponding author upon request.

\section{Ethical Approval}

Ethical clearance was granted by the ethical review committee of the Department of Pharmacy, Adigrat University, and the study was approved by the ethical review board of the city health office.

\section{Consent}

Consent for participation in the study was directly obtained from the householders prior to data collection.

\section{Disclosure}

This manuscript is based on a thesis by Mubarek Ahmedin (primary researcher), conducted at Adigrat city.

\section{Conflicts of Interest}

The authors declare that they have no conflicts of interest.

\section{Authors' Contributions}

$\mathrm{MA}, \mathrm{BK}$, and $\mathrm{KG}$ contributed to the compiling and writing of the manuscript. HK and HA provided consultancy on study conception, study design, and data analysis. DT was responsible for overall supervision. All authors read and approved the final manuscript. 


\section{Acknowledgments}

The authors would like to acknowledge the data collectors for their tireless effort in the data collection process. The authors also express their deepest appreciation for the respondents for giving their precious time during the interview and for Adigrat city administrative for facilitating this study. The primary researcher funded the study independently.

\section{References}

[1] B. Halling-Sorensen, S. Nors Nielsen, P. F. Lanzky, F. Ingerslev, H. C. HoltenLutzhoft et al., "Occurrence, fate and effects of pharmaceutical substances in the environment--a review," Chemosphere, vol. 36, pp. 357-393, 1998.

[2] World Health Organization (WHO), Promoting Rational Use of Medicines: Core components. WHO Policy Perspectives on Medicines, No. 5, World Health Organization, Geneva, Switzerland, 2002, http://www.who.int/medicines/.

[3] WHO, Challenges in Expanding Access to Essential Medicines, World Health Organization, Geneva, Switzerland, 2014, http://apps.who.int/medicinedocs/en/d/Js5571e/2.html.

[4] C. G. Daughton and T. A. Ternes, "Pharmaceuticals and personal care products in the environment: agents of subtle change?" Environmental Health Perspectives, vol. 107, no. 6, pp. 907-938, 1999.

[5] V. Anandi, "Law, prashant sakharkar, amir zargarzadeh, bik WaiBilvick tai, karl hess, micah hata, rudolph mireles, carolyn ha, tony J. Park, J.D. Taking stock of medication wastage: unused medications in US households," Research in Social and Administrative Pharmacy, vol. 11, pp. 573-574, 2015.

[6] Z. Khalid labu1, Md Mir, A. Al-Mamun1, M. d. Harun-orRashid, and K. Sikder, "Knowledge, awareness and disposal practice for unused medications among the students of the private university of Bangldesh," Journal of Biomedical and Pharmaceutical Research, vol. 2, no. 2, pp. 26-33, 2013.

[7] S. Aditya, "Safe medication disposal. Need to sensitize undergraduate students," International Journal of Pharmacy and Life Sciences, vol. 4, no. 3, pp. 2475-2480, 2013.

[8] A. Y. C. Tong, B. M. Peake, and R. Braund, "Disposal practices for unused medications around the world," Environment International, vol. 37, no. 1, pp. 292-298, 2011.

[9] R. Lagishetty, P. Nagarajan, and S. S. Vijayanandhan, "Practice towards disposal of medicines (left out/expired drugs) among the patients visiting tertiary care teaching hospital and primary health centre in South India," Asian Journal of Biochemical and Pharmaceutical Research, vol. 4, no. 1, pp. 175-182, 2013.

[10] R. Ahmed and A. Alareefi, "Patient opinion and practice toward unused medication disposal," Thai Journal of Pharmaceutical Science, vol. 34, pp. 117-120, 2013.

[11] S. Siler, S. Duda, R. Brown, J. Gbemudu, S. Weier, and J. Glaudemans, Safe Disposal of Unused Controlled Substances, King Pharmaceuticals, Bristol, TN, USA, 2009.

[12] F. S. Teni, A. S. Surur, A. Belay et al., "A household survey of medicine storage practices in Gondar town, northwestern Ethiopia," BMC Public Health, vol. 17, no. 1, pp. 1-9, 2017.

[13] S. A. Angi and S. A. Bukachi, "Household knowledge and perceptions on disposal practices of unused medicines in Kenya," Journal of Anthropology and Archaeology, vol. 4, no. 2, pp. 1-20, 2016.
[14] S. T. Glassmeyer, E. K. Hinchey, S. E. Boehme et al., "Disposal practices for unwanted residential medications in the United States," Environment International, vol. 35, no. 3, pp. 566-572, 2009.

[15] M. Bashaar, V. Thawani, M. A. Hassali, and F. Saleem, "Disposal practices of unused and expired pharmaceuticals among general public in Kabul," BMC Public Health, vol. 17, no. 1, pp. 1-8, 2017.

[16] A. K. Azad, R. Haque, A. Akhtaruzzaman, S. M. M. Almamun, M. Uddin, and M. M. Rahman, "Disposal practice for unused medications among the students of the international islamic university Malaysia," Journal of Applied Pharmaceutical Science, vol. 2, no. 7, pp. 101-106, 2012.

[17] Y. Ayele and M. Mamu, "Assessment of knowledge, attitude and practice towards disposal of unused and expired pharmaceuticals among community in Harar city, Eastern Ethiopia," Journal of Pharmaceutical Policy and Practice, vol. 9, no. 11, pp. 1-7, 2018.

[18] S. E. Cosgrove, K. S. Kaye, G. M. Eliopoulous, and Y. Carmeli, "Health and economic outcomes of the emergence of thirdgeneration cephalosporin resistance in Enterobacter species," Archives of Internal Medicine, vol. 162, no. 2, pp. 185-190, 2002.

[19] M. Bashaar, V. thawani, A.H. Mohamed, and F. Saleem, "Disposal practices of unused and expired pharmaceuticals among general public in Kabul, Afghanistan," BMC Public Health, vol. 17, no. 45, pp. 1-2, 2017.

[20] A. Ahmed, M. T. NousheenMushtaq, S. A. MalihaDurrani, M. Arif, and G. Yasmeen, "Disposal practices of unused and expired 21 pharmaceuticals in Karachi and their impact on health and environment," Journal of University Medical \& Dental College, vol. 4, no. 2, pp. 42-44, 2013.

[21] S. Sonowal, C. Desai, J. Kapadia, and M. Desai, "A survey of knowledge, attitude, and practice of consumers at a tertiary care hospital regarding the disposal of unused medicines," Journal of Basic and Clinical Pharmacy, vol. 8, no. 1, pp. 4-7, 2017.

[22] A. Auta, D. Shalkur, S. Omale, and A. H. Abiodun, "Unused medicines in Nigerian households: types and disposal practices," Journal of Pharmacology and Pharmacotherapeutics, vol. 2, no. 3, pp. 195-196, 2011.

[23] R. L. Franklin and G. B. Rodgers, "Unintentional child poisonings treated in United States hospital emergency departments: national estimates of incident cases, population-based poisoning rates, and product involvement," Pediatrics, vol. 122, no. 6, pp. 1244-1251, 2008.

[24] R. Braund, B. M. Peake, and L. Sheiffelbien, Disposal Practices for Unused Medications in New Zealand, Environmental Institute, Stockholm, Sweden, 2009.

[25] A. Lamb, Pharmacists' Role in Safe and Legal Medication Disposal, Springer, Berlin, Germany, 2012.

[26] M. Persson, E. Sabelström, and B. Gunnarsson, "Handling of unused prescription drugs - knowledge, behaviour and attitude among Swedish people," Environment International, vol. 35, no. 5, pp. 771-774, 2009.

[27] B.-D. Hwang, "Storage and disposal of unused medications for housewives in the Busan Metropolitan City," The Korean Journal of Health Service Management, vol. 7, no. 2, pp. 69-79, 2013.

[28] A. Shah, S. Parmar, A. Kumkishan, and A. Mehta, "Knowledge, attitude and practice (KAP) survey regarding the safe use of medicines in rural area of Gujurat," Advance Tropical Medicine and Public Health International, vol. 1, no. 2, pp. 66-70, 2011. 
[29] C. Bond, A. Blenkinsopp, and D. K. Raynor, "Prescribing and partnership with patients," British Journal of Clinical Pharmacology, vol. 74, no. 4, pp. 581-588, 2012.

[30] ONDCP, "Proper disposal of prescription," in Office of $\mathrm{Na}$ tional Drug Control Policy, Washington, D.C.,USA, 2009, https://www.ncjrs.gov/22.

[31] American Pharmacists Association, American Pharmacists Association, APhA Provides Guidance on Proper Medication Disposal: Use with Respect and Discard with Care, , D.C., USA, 2013.

[32] United States Food and Drug administration, How to Dispose Unused Medications, FDA, MA, USA, 2011. 